\title{
Positive effects of ectomycorrhizal colonization on growth of seedlings of a tropical tree across a range of forest floor light conditions
}

\author{
Philippe Saner • Christopher Philipson • \\ Robert C. Ong • Noreen Majalap • Simon Egli • \\ Andy Hector
}

Received: 25 March 2010 /Accepted: 23 August 2010/Published online: 11 September 2010

(C) Springer Science+Business Media B.V. 2010

\begin{abstract}
In a shadehouse experiment we tested the effects of light, nutrients and ectomycorrhizal fungi (EMF) on the growth of Vatica albiramis van Slooten (Dipterocarpaceae) seedlings. We hypothesised that it is more advantageous for plants to form connections with EMF and to trade carbon for nutrients with EMF under high light than low light. The relationship between seedling growth and the proportion of ectomycorrhizal root tips was expected as positive in high light and as negative in low light. Light conditions simulated the forest understory (low; 3\% full sunlight), a small gap (medium; 11\%) and a large
\end{abstract}

Responsible Editor: Thom W. Kuyper.

Electronic supplementary material The online version of this article (doi:10.1007/s11104-010-0555-3) contains

supplementary material, which is available to authorized users.

P. Saner $(\bowtie) \cdot$ C. Philipson $\cdot$ A. Hector

Institute of Evolutionary Biology and Environmental

Studies, University of Zurich,

Winterthurerstrasse 190,

CH-8057 Zurich, Switzerland

e-mail: psaner@uwinst.uzh.ch

R. C. Ong $\cdot$ N. Majalap

Forest Research Centre, Forestry Department Sabah,

P.O. Box 1407,

90715 Sandakan, Sabah, Malaysia

S. Egli

Swiss Federal Research Institute WSL,

Zurcherstrasse 111,

CH-8903 Birmensdorf, Switzerland gap (high; 33\%) and a fully factorial combination of nutrients $(\mathrm{F}-/+)$ and ectomycorrhizal colonization $(\mathrm{EMF}-/+)$ treatments were applied within light conditions. The application of EMF and nutrients did significantly alter seedling growth across the range of forest floor light conditions, however the key hypothesis was rejected as seedling growth under low light was not affected by increased EMF colonization of root tips (light:EMF colonization $\chi^{2}=2.97, p=0.23$ ). In addition, the lack of difference in morphotype abundance across light conditions indicated that light changes may not favour the association to specific EMF in seedlings of this particular dipterocarp species. Our results suggest that antagonistic (nonbeneficial to the plant) effects due to ectomycorrhizal colonization under a light constrained environment may not affect seedling growth of Vatica albiramis.

Keywords Vatica albiramis · Dipterocarp · Borneo · Ectomycorrhizal colonization $\cdot$ Soil solarization

\section{Introduction}

The exploitation of tropical forests for timber in Malaysian Borneo has severely degraded the condition of this fragile ecosystem since the 1980s (Marsh and Greer 1992). Rising awareness that degraded forest can be restocked with native timber trees resulted in active research on forest rehabilitation during the 1990s (Appanah 2001). In North 
Borneo members of the Dipterocarpaceae family are predominantly used for forest rehabilitation due to their ecological and economic importance (Ashton 1982; Romell et al. 2008; Symington 1943). External factors that affect dipterocarp seedling growth and survival in logged forests were identified as soil compaction along log landings and skid trails (Nussbaum et al. 1996), reduced light levels due to intervening vegetation (Bebber et al. 2002), nutrient limitation due to topsoil disturbance (Nussbaum et al. 1995) and inadequate ectomycorrhizal formation (Lee et al. 1995; Turner et al. 1993). As a result a number of studies addressed the importance of light, nutrients and ectomycorrhizal colonization for successful growth in line with efforts to plant native trees into logged forest (Lee and Alexander 1994). Studies from a shadehouse experiment and a field study on the growth of Hopea odorata (Dipterocarpaceae) showed a positive correlation between light and nutrient supply (Kamaluddin and Grace 1996; Raja Barizan 1996). The combined positive effect of dipterocarp ectomycorrhizal colonization with nutrient availability was documented in pot studies with seedlings of Dryobalanops lanceolata, Hopea nervosa and Parashorea tomentella (Brearley 2003; Lee and Alexander 1994). Later studies showed that both light and nutrients, in particular phosphorus, are a limiting resource for dipterocarp seedling growth in the understory of tropical forests in Borneo (Brearley et al. 2007). To our knowledge, this is the only study that tested for combined effects of light, nutrients, ectomycorrhizal colonization and ectomycorrhizal diversity on dipterocarp (Shorea leprosula and Hopea nervosa) growth. Since the ectomycorrhizal colonization of seedlings was shown to affect the successful growth and establishment, a more detailed understanding of this interaction is of interest for ongoing forest restoration efforts.

Ectomycorrhizal fungi (EMF) are known to be beneficial for plant growth because they possess the ability to break down the structure of plant litter and absorb nitrogen and phosphorus from plant polymers that are transferred to the plant through ectomycorrhized root tips (Selosse et al. 2006). In return fungi receive carbohydrates and vitamins from the host-plant. This association is generally seen as beneficial, however Johnson et al. (1997) highlighted that carbon allocated to fungi is a cost if it could otherwise have been allocated to increase plant fitness. Under limiting resources the plant-fungi interaction could change from benefit to cost, resulting in a continuum of behaviors ranging from mutualistic to antagonistic (non-beneficial to the plant). We tested whether light, nutrient addition and root tip colonization with EMF and their interaction affect the growth of Vatica albiramis van Slooten seedlings in a controlled experiment. It was expected that forest floor light conditions influence carbon fixation by seedlings and may therefore alter the potential value of carbohydrates to the plant. In high light conditions, carbon fixation through the process of photosynthesis is expected to be high and growth may often be limited by nutrient and water supply, therefore the relative value of carbon to the plant is low. In contrast, in low light conditions, carbon fixation and the allocation of carbon to root tip production and to trade for nutrients is expected to be low and the relative value of carbon to the plant was predicted to be higher. It was therefore hypothesised that light and EMF would interact in such a way, that seedlings in light limited conditions would benefit less from EMF colonization than seedlings in high light conditions. The relationship between EMF root tip colonization and plant relative mass growth was examined to test whether it was consistent under constant light conditions. Because the relationship may change due to the altered community composition of EMF we also examined the ectomycorrhizal morphotypes associated to the light conditions. The experimental design further allowed to test if the applied method of soil solarization followed by EMF inoculation and nutrient addition did increase seedling mass growth (RGR) relative to solarization alone. Soil solarization is commonly used in large nurseries for soil drying prior to potting of seedlings, however to what extent such treatment reduces EMF in the soil, and therefore alters seedling growth, is not well understood for dipterocarps raised under nursery conditions.

\section{Material and methods}

Experimental set up

Our study site (N0505'20" E117³8'32", 102 m.a.s.1.) was located in the Malua Forest Reserve in the eastern 
part of the state of Sabah in Malaysian northern Borneo. The shadehouse experiment was situated in logged lowland mixed dipterocarp forest that is aseasonal with an annual rainfall of approximately $3000 \mathrm{~mm}$ during the measurement period (Saner et al. 2009). A total of fifteen shadehouses ( $4 \mathrm{~m}$ high $\times 5 \mathrm{~m}$ wide $\times 6 \mathrm{~m}$ long) were aligned in five blocks of three shadehouses, randomly allocated to one of three light conditions. To minimise self-shading blocks were sited along an east-west line with $3 \mathrm{~m}$ space between the houses and $>10 \mathrm{~m}$ between blocks. We simulated three light conditions by using a triple, a double and a single layer of $70 \%$ black shade cloth: the forest understory (low; 3\% full sunlight), a small gap (medium; 11\%) and a large gap (high; 33\%). Environmental measures were taken inside all shadehouses for 1 day each (12th-26th July 2007) between 08:00 and 16:00 with a data logger (Lynx data hog, Skye, USA). The data logger was set to record measurements from photosynthetic active radiation (PAR), red light, far red light, relative humidity and temperature sensors every $30 \mathrm{~s}$ and to record average values every $10 \mathrm{~min}$ (Table 1). Light readings outside were collected every hour with a quantum sensor (LI-189, LiCor, USA) to calculate relative light availability inside the shadehouses. Light sensors inside the shadehouse and outside (Skye Quantum and LiCor LI-189) were calibrated before measuring by comparing means per hour over a full day. Within shadehouses wire mesh protected the seeds from mammal damage and pots were spaced $0.3 \mathrm{~m}$ apart. The design was fully factorial and controlled for light, nutrient addition and EMF. Seeds were planted into soil where nutrients were applied $(\mathrm{F}+)$ or not $(\mathrm{F}-)$ and where EMF where added (EMF+) or not (EMF-) and randomly allocated to the shadehouses and to one of four treatments (F-/EMF-, F-/EMF+, F+/EMF-, F+/EMF+). We used the sample function in $\mathrm{R}$ (R Development Core Team 2009) for randomization.
Seed material

The choice of the experimental species was determined by seed availability, since dipterocarps fruit irregularly and seeds germinate quickly after desiccation under moist and warm conditions (Appanah and Turnbull 1998). Vatica albiramis (local name resak puteh) belongs to the vernacular group of resak, a heavy hardwood (880-990 $\mathrm{kgm}^{-3}$ at $15 \%$ moisture content). Its relative abundance in the Malua Forest Reserve is $0.6 \mathrm{~m}^{2} \mathrm{ha}^{-1}$ (Saner 2009). Besides its timber usage it is also known as a non-timber forest product. The Dayak people of central Kalimantan use an extract of Vatica albiramis as a pest and disease protection during rice cultivation (Limin et al. 2007). Seeds of two Vatica albiramis trees were collected directly from the branch to ensure that seedlings would not already be colonized by EMF before the experiment started. Seeds were numbered individually, weighed and germinated in sterilised plastic boxes to test for viability before planting them into the soil $(n=$ 776). Germination started after 1 week and lasted for 19 days. A total of 489 (63\%) seeds germinated and a random selection thereof was used for the experiment. Initial seed mass was measured to calculate the relative growth rate with initial seed mass as a covariate (see Appendix Table S1).

\section{Soil source}

The subsoil used is classified as orthic acrisol, which is acidic $(\mathrm{pH}=5.1)$, highly weathered, with low nutrient availability (Table 2). Initial soil treatment is crucial for the establishment and resistance of the seedling stock and for a later success of the replanting effort (Moura-Costa et al. 1994). However, careless soil treatment is widespread in nurseries after the soil has been excavated in the field (personal observation). Due to the high clay content the soil is normally dried for at least 1 week. Then, the soil is shredded to small
Table 1 Environmental conditions (mean \pm SEM) within three shadehouse light conditions (low, medium, high), representing the forest understory, a small and a large gap. PAR* is reported as the percentage of outside light conditions

\begin{tabular}{llllc}
\hline & Unit & Low & Medium & High \\
\hline PAR $^{*}$ & $\%$ & $2.6 \pm 0.6$ & $10.8 \pm 1.3$ & $32.9 \pm 4.5$ \\
PAR & $\mu$ molm $^{-2} \mathrm{~s}^{-1}$ & $11.7 \pm 2.3$ & $42.9 \pm 4.9$ & $127.5 \pm 13.2$ \\
Red / Far Red & Ratio & $0.92 \pm 0.08$ & $0.87 \pm 0.04$ & $0.85 \pm 0.06$ \\
Relative Humidity & $\%$ & $81.3 \pm 2.5$ & $80.1 \pm 0.6$ & $80.9 \pm 2.4$ \\
Temperature & ${ }^{\circ} \mathrm{C}$ & $27.3 \pm 0.6$ & $27.3 \pm 0.2$ & $27.0 \pm 0.5$ \\
\hline
\end{tabular}


Table 2 Mean $( \pm$ SEM) analysis of the soil/sand mixture for the control $(\mathrm{F}-, n=3)$ and the nutrient addition $(\mathrm{F}+, n=3)$ of the first harvest. Nutrients were added at the start (day 0 ) and after the first (day 143) and second (day 283) harvest to the remaining seedlings. N: Nitrogen, P: Phosphorous, K: Kalium, $\mathrm{Mg}$ : Magnesium, Ca: Calcium, Mn: Mangan, ECEC: Effective cation exchange capacity, Bsat: Base saturation (see text for method details). *Note that at this point (first harvest, 143 days after experimental start) only the $\mathrm{pH}$ significantly differed between the fertilizer treatments

\begin{tabular}{llcc}
\hline & Unit & F- & \multicolumn{2}{l}{$\mathrm{F}+$} \\
\hline $\mathrm{pH}^{*}$ & $\mathrm{H}_{2} \mathrm{O}$ & $5.1 \pm 0.1$ & $4.6 \pm 0.1$ \\
Total N & $\%$ & $0.06 \pm 0.01$ & $0.07 \pm 0.01$ \\
Total P & $\mathrm{\mu gg}^{-1}$ & $22.6 \pm 2.6$ & $59.3 \pm 22.9$ \\
Extractable $\mathrm{K}$ & $\mathrm{m}^{-e q u i v .}$ & $0.16 \pm 0.01$ & $0.42 \pm 0.12$ \\
Extractable $\mathrm{Mg}$ & $100 \mathrm{~g}^{-1}$ & $2.6 \pm 0.1$ & $2.5 \pm 0.1$ \\
Extractable Ca & & $7.5 \pm 0.5$ & $7.2 \pm 0.3$ \\
Extractable $\mathrm{Mn}$ & & $0.03 \pm 0.01$ & $0.05 \pm 0.01$ \\
ECEC & & $12.7 \pm 0.4$ & $12.8 \pm 0.3$ \\
Bsat & $\%$ & $81.3 \pm 2.1$ & $79.0 \pm 2.3$ \\
\hline
\end{tabular}

pieces with a rotating conveyer belt (model 110, Royer, USA) to discharge stones and woody debris (J.Abun, pers. comm.). Drying and heating of the soil (soil solarization) may kill existing mycorrhizal spores and hyphae. Subsequent rewetting may also have major impacts on soil chemistry and biology, including a flush of soil nutrients resulting from death of microbes and potentially dampening effects of nutrient addition on early seedling growth in pots. For this study subsoil was shredded, then solarized twice for 3 days consecutively under black plastic $\left(>60^{\circ} \mathrm{C}\right)$ following the method described in Yasman (1995). Shredded subsoil treated similarly is readily used in nurseries to raise seedling stocks for forest rehabilitation efforts. We ensured that the soil remained in wet condition always to prevent altered soil structure. River sand was boiled with sufficient water in half a barrel for approximately $30 \mathrm{~min}$ over a fire. Solarized soil was then mixed with the boiled river sand (ratio 2:1) for easier excavation of the root system and associated EMF. The soil/sand mixture was filled into black polyethylene bags $(0.2 \mathrm{~m}$ wide $\times 0.3 \mathrm{~m}$ deep $)$.

\section{Experimental phase}

A total of twenty germinated seeds were replaced during the 2 weeks establishment phase prior to experimental start. A germinated seed was considered dead if it was washed out of the soil and the roots were dry or black, if the endosperm was entirely missing or if the cotyledons were cut off. The experiment started on the 21st of July 2006. During the length of the experiment (410 days) an additional eleven seedlings died (94\% survival) and were replaced. The reported mean relative growth rate (RGR) can therefore be interpreted as a population-level average response across all seedlings. Full replications of the experimental design $(n=60 ; 3$ light conditions $\times 2$ nutrient treatments $\times 2$ ectomycorrhizal colonization treatments $\times 5$ replicate blocks) were harvested 143 days (first), 283 days (second) and 410 days (final harvest) after the start. At each harvest we washed the soil and sand mixture carefully off the roots and randomly selected five fine roots $(>2 \mathrm{~mm}$ diameter) of the entire root system. The presence of ectomycorrhizal colonization was then counted on 200 root tips of the selected fine roots of every seedling to estimate the percentage of ectomycorrhizal colonization and the associated morphotypes following the description of Agerer and Rambold (2004-2007) (Appendix Table S2). Leaves, shoots and roots of the seedlings were separated, oven dried to constant weight $\left(72 \mathrm{~h}, 65^{\circ} \mathrm{C}\right)$ and individually measured.

\section{Soil analysis}

Air-dried samples of the soil/sand potting mixes were ground to pass through a 2-mm sieve and analysed for $\mathrm{pH}$, total $\mathrm{N}$ and $\mathrm{P}$, extractable $\mathrm{K}, \mathrm{Mg}, \mathrm{Ca}, \mathrm{Mn}$ and effective cation exchange capacity (ECEC) (detailed protocols in Majalap and Chu (1992)). The $\mathrm{pH}$ was measured with a combination glass-calomel electrode (pH Meter Model 140, Corning, UK) in a 1:2.5 ratio of soil to distilled water suspension. Total $\mathrm{N}$ was determined following the Kjeldahl digestion described by Bremner (1965) on a block digestor and the digest measured for nitrogen content (SFA2 autoanalyser, Burkard, UK). Extraction of soil available P followed the method of Bray and Kurtz (1945) and the $\mathrm{P}$ content in the extract was measured as described in Anderson and Ingram (1993). For the determination of $\mathrm{K}, \mathrm{Mg}, \mathrm{Ca}, \mathrm{Mn}$ the soil was leached with $1 \mathrm{M}$ ammonium acetate (Gillman et al. 1983) and the leachate analysed for each element on an atomic absorption spectrophotometer (GBC 932, 
GBC Scientific Equipment Pvt. Ltd, Australia). The ECEC was taken as the sum of the exchangeable base cations plus the exchangeable acidity. To determine the exchangeable acidity, the soil was leached with $1 \mathrm{M}$ potassium chloride and titrated with $0.1 \mathrm{~N}$ sodium hydroxide (Anderson and Ingram 1993). Base saturation (Bsat) was taken as the percentage of the ECEC occupied by the exchangeable bases.

Treatment efficacy for light, nutrient addition and EMF inoculation

The light conditions were representative for the surrounding 22-year old logged forest of the Malua Forest Reserve. Our measurements within the area on 1435 dipterocarp seedlings showed that the light conditions were between $0-26 \%$ photosynthetic active radiation (PAR) (Saner 2005). A total of 519 $(36 \%)$ seedlings grew in light conditions of $0-2 \%$ PAR, 701 (49\%) in 3-6\% PAR and 215 (15\%) in 7$26 \%$ PAR. Measurements were taken with a spherical densiometer (Lemmon 1956).

Agroblen (Scotts PBG Malaysia Sdn. Bhd., Selangor, Malaysia) 6-months slow release fertilizer (16:8:9:3, N:P:K:Mg + trace elements) was added to $\mathrm{F}+$ treatments at the start of the experiment and subsequently at every harvest to the remaining seedlings. During the course of the experiment (410 days) $1.25 \mathrm{~g}$ fertilizer was applied three times on $5 \mathrm{~kg}$ soil. Analysis of the soil/sand mixture after the first harvest (143 days after experimental start) showed that the $\mathrm{F}+$ treatment was significantly more acidic $(\mathrm{t}=3.5, \mathrm{df}=4, p<0.05)$, however nutrients did not differ at this point between treatments (Table 2). We tested for the effect of fertilizer treatment on seedling total mass, because this validates if the fertilizer treatment worked. For the first harvest (143 days) the effect was marginal $\left(\mathrm{F}_{1,35}=\right.$ $3.0, p<0.1)$. For the second (283 days) and the third harvest (410 days) the effect was significant $\left(\mathrm{F}_{1,35}=\right.$ $11.4, p<0.002$ and $\mathrm{F}_{1,35}=20.5, p<0.0001$ respectively). We therefore conclude that the fertilization treatment induced a significant difference in seedling mass.

The non-ectomycorrhizal seeds described above were carefully planted into the polyethylene bags. $\mathrm{EMF}+$ treatments were inoculated with a $2: 1$ mixture of the forest humus layer $(0-5 \mathrm{~cm}$ soil depth collected under the mother tree) and nursery soil. The inoculum was kept wet to prevent from desiccation until further processing and mixed thoroughly by hand. A total amount of $350 \mathrm{ml}$ of the inoculum was poured onto the germinated EMF + seeds to ensure high colonization levels at the experimental start. Efforts were taken to minimise the natural infection of root tips with EMF of the untreated seedlings (EMF-). In particular we reduced the spraying with water between treatments to minimise water droplets and we avoided touching the soil. No fungicide treatment was applied to control for ectomycorrhizal colonization. Seedlings were watered regularly to avoid desiccation and relocated twice within the shadehouses to avoid positioning effects.

Seedlings that were inoculated with EMF $(\mathrm{EMF}+)$ initially showed increased levels of ectomycorrhizal colonized root tips for the medium and the high light condition where no nutrients were added (F-/EMF+; $27-28 \%$ increase) and where nutrients were added ( $\mathrm{F}+$ / EMF+; 28-33\% increase) compared to the control (F-/ EMF- and F+/EMF-). This confirmed that the soil solarization and the ectomycorrhizal inoculation procedure induced a measurable difference in EMF colonization between treatments (Fig. 1a). For the subsequent harvests the effect disappeared and EMF colonized root tips increased with light conditions and over time (Fig. 1abc).

\section{Statistical analysis}

All analysis and graphical presentation was performed in R (R Development Core Team 2009). The experimental design included fixed and random effects. Light conditions (low, medium, high), nutrient addition (F-, F+) and ectomycorrhizal colonization $(\mathrm{EMF}-\mathrm{EMF}+)$ were treated as fixed effects, block $(n=5)$ and shadehouses $(n=15)$ were treated as random terms. A separate test was performed for each of the harvests on day 143, 283 and 430 after experimental start. We checked for normally distributed residual errors during analysis.

Root tip colonization with EMF and seedling growth

We used the lme function (Pinheiro and Bates 2000) implemented in the nlme package for $\mathrm{R} 2.9 .0$ to analyse root tip colonization with EMF and seedling relative mass growth. Root tip colonization (percent- 
Fig. 1 Inoculation with EMF (mean \pm SEM) significantly increased the colonization with ectomycorrhizal root tips in the medium and high light condition, but not in the low light of the first harvest (a). For the second (b) and the third (c) harvest the EMF inoculation treatment disappeared, except for the low light of the third harvest. Note that the nutrient treatments $(\mathrm{F}+/ \mathrm{F}-)$ were pooled. $\mathrm{EMF}+$ : inoculated with ectomycorrhizal fungi (including $\mathrm{F}+/ \mathrm{EMF}+$ and F-/EMF+); EMF-: control (including $\mathrm{F}-\mathrm{EMF}-$ and $\mathrm{F}+/ \mathrm{EMF}-$ )
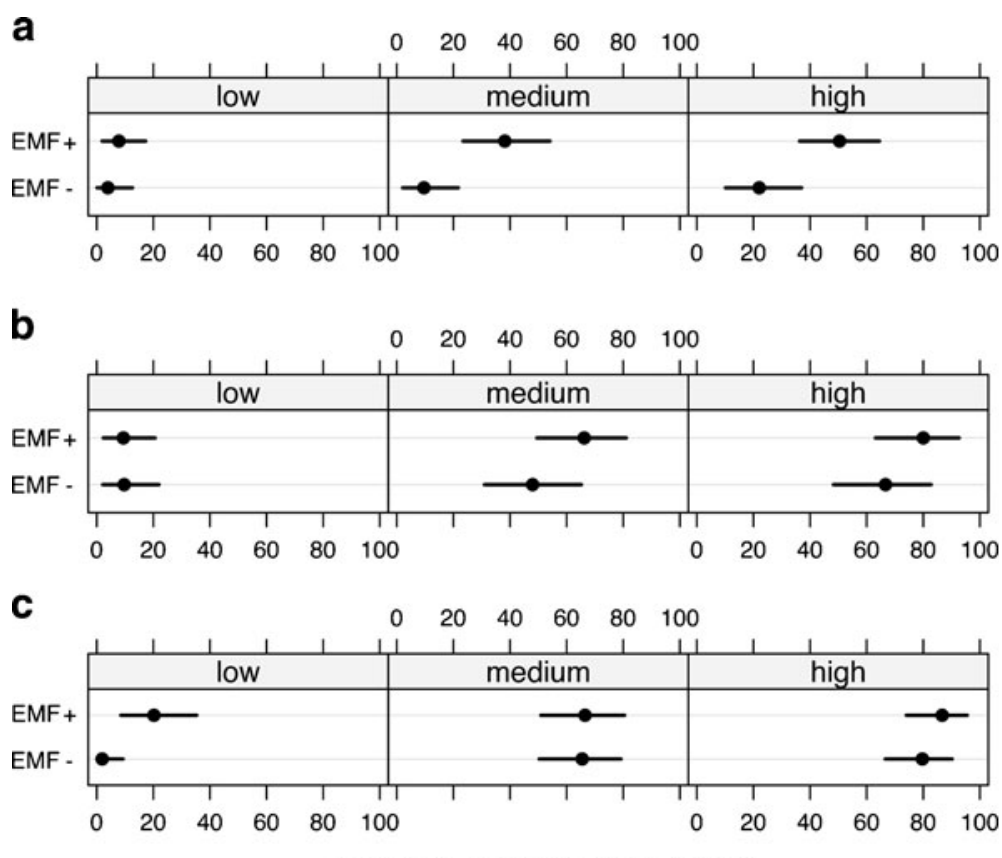

Root tips colonized with EMF (\%) age) per seedling was arcsin square root transformed for analysis and back transformed for ease of interpretation. Relative growth rate of total mass (RGR; $\mathrm{gg}^{-1} \mathrm{day}^{-1}$ ) was reported on the assumption that a higher seedling mass growth reflects a higher overall plant fitness (Hunt 1990):

$\mathrm{RGR}=\frac{\log _{e} \mathrm{~W}_{2}-\log _{e} \mathrm{~W}_{1}}{\mathrm{~T}_{2}-\mathrm{T}_{1}}$

RGR was calculated as change in log total mass $\left(\log \mathrm{W}_{2}-\log \mathrm{W}_{1}\right)$ divided by the time interval $\left(\mathrm{T}_{2}-\mathrm{T}_{1}\right)$. Relative growth examines growth on a percentage basis, where taking the logarithm of the mass is based on the assumption that the seedlings grow at a constant exponential rate (Philipson 2009). Initial size-corrected average relative growth rate (RGR) corrected for differences in initial seed mass was used as a measure of individual seedling performance under the different light conditions (Nicieza and Alvarez 2009). However, because this study examines a single species, rather than multiple species where initial sizes may vary with species, the variation in starting sizes was small (Appendix Table S1). Initial total seed mass for analysis was derived from a selection of viable seeds $\left(n=34,72 \mathrm{~h}, 65^{\circ} \mathrm{C}\right)$ with an allometry $\left(\mathrm{R}^{2}=0.9\right.$, dry mass $=-0.04+0.56$ (wet mass)).
Morphotype abundance

Diversity of morphotypes (count) was analysed with a generalised linear mixed effects model using the $\operatorname{glmmPQL}$ function from the MASS package (Venables and Ripley 2003), where the family was set as quasipoisson. Model checking was performed with the binnedplot function of the arm package (Gelman and Hill 2007).

\section{Results}

Relative seedling mass growth (RGR)

Analysis of RGR until the first harvest revealed that the three way interaction and all two way interactions were non-significant and therefore removed from the model (EMF:nutrient:light, log likelihood ratio statistic: $\left.\chi^{2}=9.89, p=0.19\right)$. For the first harvest light significantly increased RGR by $43 \%$ in the $11 \%$ PAR treatment and by a further $57 \%$ in the 33\% PAR treatment ( $\left.\mathrm{F}_{2,8}=44.0, p<0.0001\right)$. Both EMF and nutrient addition did not significantly alter growth (Fig. 2a). For the second harvest a significant light and nutrient interaction was observed $\left(\mathrm{F}_{2,37}=12.6, p<0.0001\right)$, which indicated that 
Fig. 2 Effect of nutrients, ectomycorrhizal fungi (EMF) and light condition on relative growth rate (RGR) for the three growth intervals: a first harvest, b second harvest, $\mathbf{c}$ third harvest. RGR (mean $\pm \mathrm{SEM}$ ), light conditions: low, medium, high (see text for details), initial inoculation with ectomycorrhizal fungi (EMF) and nutrient (F) treatment: $\mathrm{EMF}+$; inoculated with EMF, F+; nutrient addition, EMF-; control, not inoculated, F-; control, no nutrients a

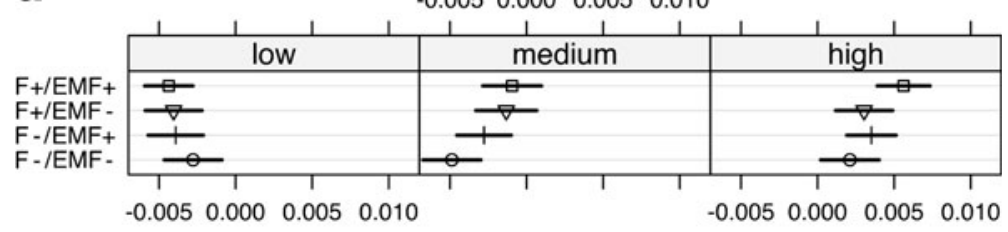

b

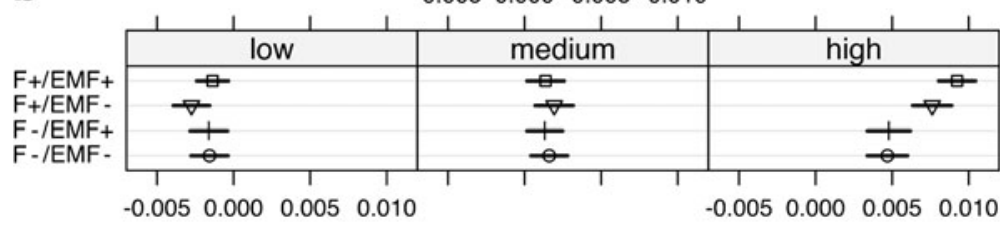

C

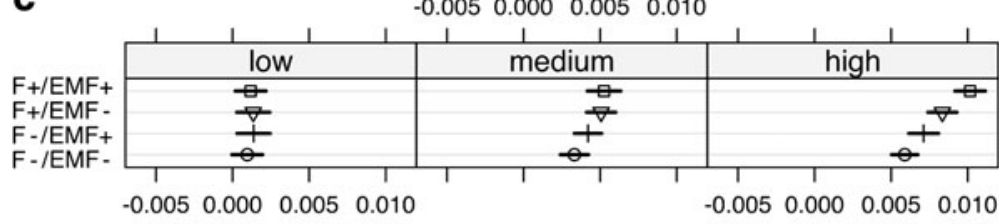

RGR Mass $\left(\mathrm{g} \mathrm{g}^{-1}\right.$ day $\left.^{-1}\right)$ seedling growth in the high light condition only was increased by nutrient addition (Fig. 2b). Again, light significantly increased RGR by $34 \%$ in the $11 \%$ PAR treatment and by a further $66 \%$ in the $33 \%$ PAR treatment $\left(\mathrm{F}_{2,8}=87.1, p<0.0001\right)$. For the third harvest the light and nutrient interaction remained significant $\left(\mathrm{F}_{2,37}=5.5, p<0.001\right)$, in addition there was a significant main effect of EMF on seedling growth $\left(\mathrm{F}_{1,37}=5.8, p=0.02\right)$ (Fig. $\left.2 \mathrm{c}\right)$. This indicated that seedling growth due to inoculation with EMF and nutrient addition increased relative to solarization alone. In contrast to our expectation the EMF colonization was not observed to interact with light conditions across all three harvests.

\section{Relating RGR to EMF root tip colonization}

The relationship between seedling growth and the proportion of ectomycorrhizal root tips was predicted as positive in high light and as negative in low light. To test whether the relationship was consistent across light conditions, seedlings of all three harvests were pooled (Fig. 3). The key hypothesis was rejected since the relationship between EMF colonization and seedling growth did not differ significantly between light conditions (light: EMF colonization $\chi^{2}=2.97, p=0.23$ ).
Morphotype abundance

In total only nine seedlings were found without ectomycorrhizal root tip colonization across all three harvests $(n=8$ in the low light, $n=1$ in the intermediate light condition). As expected, most seedlings without morphotypes were found in the untreated control (F-/EMF-; $n=5)$, followed by the nutrient treatments (F+/EMF-; $n=2$ and $\mathrm{F}+/ \mathrm{EMF}+$; $n=2)$. Altered levels of morphotype abundance (number of morphotypes on a given seedling) were only found for the intermediate light condition of the first harvest. More morphotypes were present on seedlings inoculated with EMF and without nutrient addition (F-/EMF+; Mean difference of 2.4 morphotypes; with $95 \% \mathrm{CI}=1.3-4.2)$ and with nutrient addition $(\mathrm{F}+/ \mathrm{EMF}+$; Mean difference of 1.7 morphotypes; with $95 \% \mathrm{CI}=1.1-2.7)$ compared to the controls (F-/EMF- and F+/EMF-). The difference could not be found for the low or the high light condition and disappeared for the subsequent harvests. Interestingly, despite the reduced levels of ectomycorrhizal colonized root tips in the low light, morphotype presence was similar (10-11 morphotypes) to the medium and the high light condition (12-14 morphotypes) (Appendix Table S3). Across all harvests we did not detect an overall difference in 
Fig. 3 Relationship between relative growth rate (RGR) of total seedling mass and percentage of mycorrhized root tips of all three harvests pooled. Multiple R-squared $\left(R^{2}\right)$ is reported for each light condition: a low, b medium, c high, whereby seedlings with different treatments (EMF, F) were pooled (black line). Data points and trend lines are shown for each treatment separately (darkgrey)

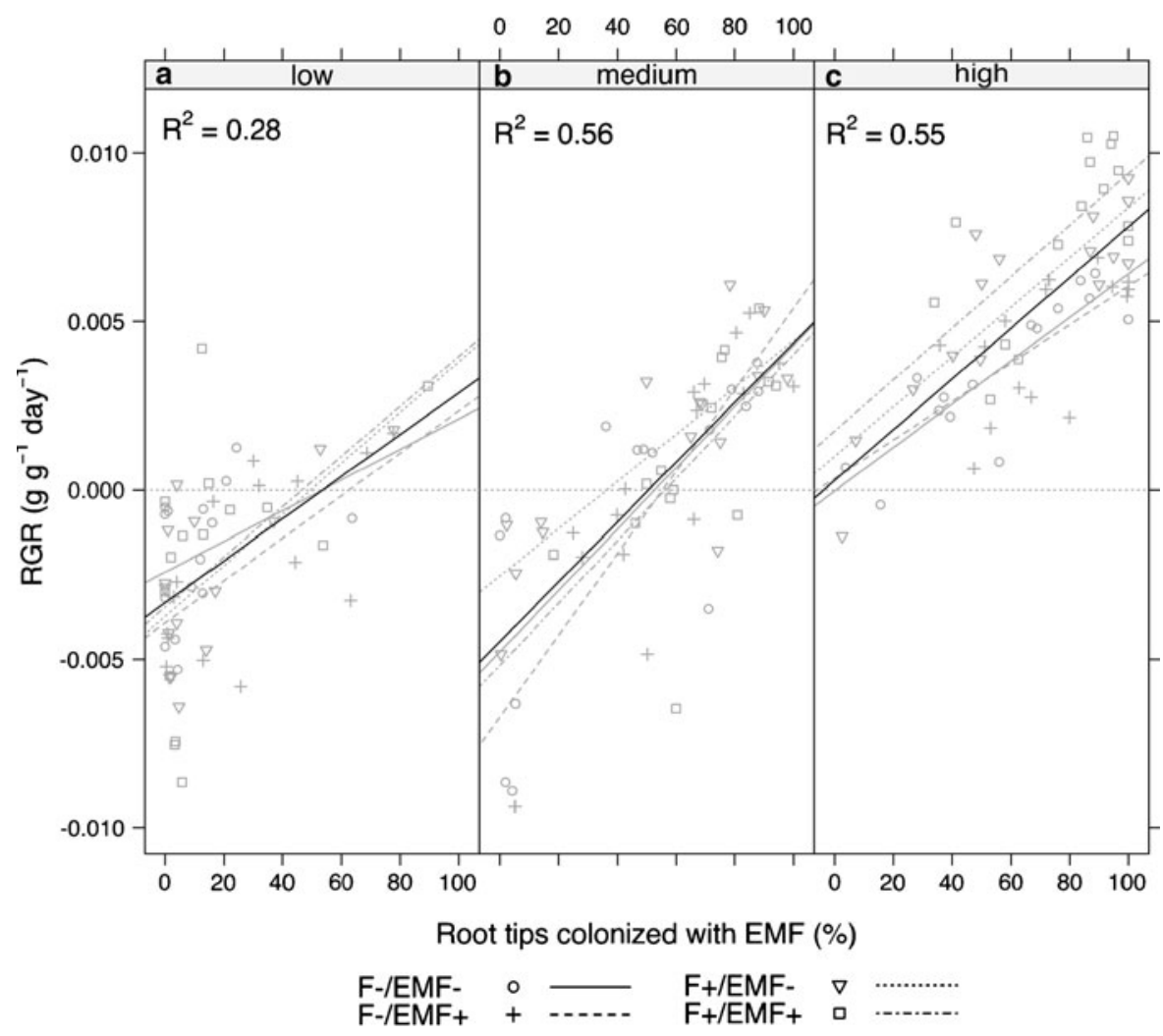

morphotype presence or absence regarding treatment levels (light, nutrient addition) (Appendix Table S3, only first harvest is shown). Morphotype differences with regard to nutrient addition were found for one morphotype (L) only.

\section{Discussion}

The findings of this study supported the rejection of the key hypothesis, namely that light and EMF colonization would interact in such a way, that seedlings in light limited conditions would benefit less from EMF colonization than seedlings in high light conditions. We found that the relationship was independent of light, suggesting that seedling growth under low light was not negatively affected by increased EMF colonization. To our knowledge this is the first study that detangles this relationship from simulated forest floor light conditions in dipterocarps.

We expected that the cost scenario is likely to occur close to the light compensation point, where the amount of carbon that is respired equals the amount that is captured through the process of photosynthesis. At this point the value of carbon to the plant is high as it could be allocated to increase plant fitness. Our results showed that seedling mass growth switched from negative to positive between the second and the third harvest (Fig. 2bc). This indicated that the low light condition (11.7 \pm $2.3 \mu \mathrm{molm}^{-2} \mathrm{~s}^{-1} \mathrm{SEM}$ ) was not dark enough to keep seedlings continually below the light compensation point. Although the light compensation point for this particular species is unknown, it was shown to vary broadly in dipterocarps and may depend on light conditions (Barker et al. 1997; Eschenbach et al. 1998). Measurements from the dark understory of undisturbed primary rainforest on Dryobalanops lanceolata and Shorea leprosula showed that absolute values were as low as $5 \mu \mathrm{molm}^{-2} \mathrm{~s}^{-1}$ (Zipperlen and Press 1996). The light conditions of this study were typically higher than in primary forests, we therefore acknowledge that the simulated light environment is not in the context within which the dipterocarp ectomycorrhizal symbiosis has evolved. If the mutualistic interaction of EMF and dipterocarps becomes negative in field conditions remains 
to be tested, since light is known to be highly heterogeneous in the understory of tropical rain forests (Bungard et al. 2002; Chazdon and Pearcy 1991; Leakey et al. 2004). Sunflecks may compensate for low light conditions if understory plants can respond to excess light (Watling et al. 1997). Such heterogeneity in light is normally not accounted for in artificial shadehouse experiments and is best simulated in natural forest conditions (Dalling et al. 1999; Dalling et al. 2004). However, the results of this study indicate that the relative value of carbon did not change close to the light compensation point, since none of the applied treatments (nutrient addition, EMF inoculation) significantly altered seedling growth in the low light. Antagonistic (nonbeneficial to the plant) effects due to ectomycorrhizal colonization under such conditions may not affect seedling growth of Vatica albiramis. In addition the results suggest that both seedling mass growth and EMF colonization of root tips subsequently increased with light and over time (Figs. 1 and 2). A significant but weak effect of EMF inoculated root tips was measured 1 year after experimental start (Fig. 2c), suggesting that time lags may be important to consider when studying the influence of ectomycorrhizal root tip colonization on seedling mass growth.

The observed positive relationship across the range of forest floor light conditions is in line with findings of previous studies (Becker 1983; Ingleby et al. 1998; Yasman 1995), and responses to high light environments may even be representative for forest-grown seedlings (Bloor 2003). However, besides the range of forest floor light conditions adaptability in seedling performance was also predicted to relate to other factors, such as the diversity and abundance of ectomycorrhizal strains (Brearley et al. 2007; Turjaman et al. 2006), or the influence of limiting nutrients such as total N (Brearley et al. 2005; Bungard et al. 2000; Burslem et al. 1995). Although we found that an increase in seedling mass growth was related to percentage of ectomycorrhizal root tips we could not relate seedling mass growth across light conditions to the abundance of individual morphotypes (Brearley et al. 2007). If these findings apply to the field situation is unknown, since seedlings that are disconnected from the mycorrhizal network (by potting them into bags) may be colonized by a different suite of fungi.
The response to nutrient addition varied according to the exposed light condition, but no response could be found in understory light conditions as suggested by Nussbaum et al. (1995). In contrast seedlings with nutrient addition had reduced levels of ectomycorrhizal root tips in high light, even though the trend was not significant and more advanced methods of soil sterilisation are necessary to test the relationship between nutrient addition and ectomycorrhizal colonization (Johnson 1993). The lack in difference between nutrient treatments after the first harvest, suggests that $\mathrm{N}$ was taken up in proportion to its availability, however the added amount of nutrients at each harvest may have been too low to induce changes in associated morphotypes. Brearley et al. (2007) reported that their hardwood species (Hopea nervosa) did not show altered growth rates with $\mathrm{P}$ fertilisation when grown in shade chambers. In contrast, the light hardwood species (Shorea leprosula) responded to $\mathrm{P}$ fertilisation with an increased growth rate and increased foliar $\mathrm{P}$ concentrations. Further studies should therefore consider other species of dipterocarps, in particular faster growing seedlings such as Shorea leprosula. These exert a greater demand for nutrients and a great range of adaptability to changes in biotic and abiotic conditions (Scholes et al. 1997). Therefore they may be predicted to be more dependent on EMF colonization to support vegetative growth.

\section{Conclusion}

We found that Vatica albiramis seedlings are associated with EMF across a range of forest floor light conditions, including the dark understory and a large gap. Our results support the rejection of the key hypothesis, namely that seedlings in light limited conditions would benefit less from EMF colonization than seedlings in high light conditions. In addition a significant but weak effect of EMF inoculated root tips was measured over 1 year after experimental start, suggesting that time lags may be important to consider when studying the influence of ectomycorrhizal root tip colonization on seedling mass growth. We conclude that antagonistic (non-beneficial to the plant) effects due to ectomycorrhizal colonization under a light constrained environment may not affect seedling growth of Vatica albiramis. 
Acknowledgements We thank: Martina Peter and Lee Su See for helpful discussion of the experimental design and morphotype identification; Charles Godfray and Glen Reynolds for their efforts in setting up and supporting the Sabah Biodiversity Experiment; Karin Beer together with research assistants from the Malua Field Station for providing field assistance; Jake Snaddon, Michael O'Brien, Thom W. Kuyper and two anonymous reviewers for comments on the manuscript. The Economic Planning Unit Sabah, Malaysia and the Danum Valley Management Committee approved this field study. This project was funded by the University Zurich, with financial support from the Darwin Initiative fund and is part of the Royal Society South-East Asia Rainforest Research Programme (Project No. RS243). This is paper no. 3 of the Sabah Biodiversity Experiment.

\section{References}

Agerer R, Rambold G (2004-2007) DEEMY - An information system for characterization and determination of ectomycorrhizae, Munich

Anderson JM, Ingram JSI (1993) Tropical soil biology and fertility - A handbook of methods, 2nd edn. CAB International, Oxford

Appanah S (2001) Sustainable management of Malaysian rainforest. In: Evans J (ed) The forests handbook volume 2. Blackwell Science, Oxford, pp 341-356

Appanah S, Turnbull JM (1998) A review of dipterocarps: taxonomy, ecology and silviculture. Center for International Forestry Research, Bogor

Ashton PS (1982) Dipterocarpaceae. Flora Malesiana 9:237552

Barker MG, Press MC, Brown ND (1997) Photosynthetic characteristics of dipterocarp seedlings in three tropical rain forest light environments: a basis for niche partitioning? Oecologia 112:453-463

Bebber D, Brown N, Speight M, Moura-Costa P, Wai YS (2002) Spatial structure of light and dipterocarp seedling growth in a tropical secondary forest. Forest Ecol Manag 157:65-75. doi:10.1016/S0378-1127(00)00659-9

Becker P (1983) Ectomycorrhizas in Shorea (Dipterocarpaceae) seedlings in a lowland Malaysian rainforest. Malaysian Forester 46:146-170

Bloor JMG (2003) Light responses of shade-tolerant tropical tree species in north-east Queensland: a comparison of forest- and shadehouse-grown seedlings. J Trop Ecol 19:163-170. doi:10.1017/S0266467403003183

Bray RH, Kurtz LT (1945) Determination of total organic and available forms of phosphorous in soils. Soil Sci 59:39-45

Brearley FQ (2003) The role of ectomycorrhizas in the regeneration of dipterocarp seedlings. Dissertation. University Sheffield

Brearley FQ, Scholes JD, See LS (2005) Nitrogen nutrition and isotopic discrimination in tropical ectomycorrhizal fungi. Res Microbiol 156:184-190

Brearley FQ, Scholes JD, Press MC, Palfner G (2007) How does light and phosphorus fertilisation affect the growth and ectomycorrhizal community of two contrasting dip- terocarp species? Plant Ecol 192:237-249. doi:10.1007/ s11258-007-9325-6

Bremner JM (1965) Total nitrogen. In: Black CA (ed) Methods of soil analysis. Part 2. Chemical and microbiological properties. American Society of Agronomy Inc, Madison, pp 1149-1178

Bungard RA, Press MC, Scholes JD (2000) The influence of nitrogen on rain forest dipterocarp seedlings exposed to a large increase in irradiance. Plant Cell Environ 23:11831194. doi:10.1046/j.1365-3040.2000.00642.x

Bungard RA, Zipperlen SA, Press MC, Scholes JD (2002) The influence of nutrients on growth and photosynthesis of seedlings of two rainforest dipterocarp species. Funct Plant Biol 29:505-515

Burslem DFRP, Grubb PJ, Turner IM (1995) Responses to nutrient addition among shade-tolerant tree seedlings of lowland tropical rain forest in Singapore. J Ecol 83:113122

Chazdon RL, Pearcy RW (1991) The importance of sunflecks for forest understory plants-Photosynthetic machinery appears adapted to brief, unpredictable periods of radiation. Bioscience 41:760-766

Dalling JW, Lovelock CE, Hubbell SP (1999) Growth responses of seedlings of two neotropical pioneer species to simulated forest gap environments. J Trop Ecol 15:827839. doi:10.1017/S0266467499001200

Dalling JW, Winter K, Hubbell SP (2004) Variation in growth responses of neotropical pioneers to simulated forest gaps. Funct Ecol 18:725-736. doi:10.1111/j.0269-8463.2004. 00868.x

Eschenbach C, Glauner R, Kleine M, Kappen L (1998) Photosynthesis rates of selected tree species in lowland dipterocarp rainforest of Sabah, Malaysia. Trees-Struct Funct 12:356-365. doi:10.1007/s004680050162

Gelman A, Hill J (2007) Data analysis using regression and multilevel/hierarchical models. Cambridge University Press, New York

Gillman GP, Bruce RC, Davey BG, Kimble JM, Searle PL, Skjemstid JO (1983) Comparison of methods used for determination of cation exchange capacity. Commun Soil Sci Plant Anal 14:1005-1014

Hunt R (1990) Basic growth analysis. Unwyn Hyman, London Ingleby K, Munro RC, Noor M, Mason PA, Clearwater M (1998) Ectomycorrhizal populations of dipterocarp seedlings regenerating under three different forest canopy treatments. Forest Ecol Manag 111:171-179

Johnson NC (1993) Can fertilization of soil select less mutualistic mycorrhizae. Ecol Appl 3:749-757

Johnson NC, Graham JH, Smith FA (1997) Functioning of mycorrhizal associations along the mutualism-parasitism continuum. New Phytol 135:575-585

Kamaluddin M, Grace J (1996) Acclimatisation of seedlings of Bischofia javanica and Hopea odorata to light and nutrient supply. In: Appanah S, Khoo KC (eds) Proceedings Fifth Round-Table Conference on Dipterocarps. Forest Research Institute Malaysia, Kuala Lumpur

Leakey ADB, Scholes JD, Press MC (2004) Physiological and ecological significance of sunflecks for dipterocarp seedlings. J Exp Bot 56:469-482. doi:10.1093/jxb/eri055

Lee SS, Alexander IJ (1994) The response of seedlings of two dipterocarp species to nutrient additions and 
ectomycorrhizal infection. Plant Soil 163:299-306. doi:10.1007/BF00007979

Lee SS, Watling R, Turnbull E (1995) Ectomycorrhizal fungi as possible bio-indicators in forest management. Conf. Forestry and Forest Products Research, pp 63-68

Lemmon PE (1956) A spherical densiometer for estimating forest over-story density. Forest Sci 2:314-320

Limin SH, Ermiasi Y, Selviana EI (2007) History of the development of tropical peatland in central Kalimantan, Indonesia. Centre for International Cooperation in Management of Tropical Peatland, Palangka Raya

Majalap N, Chu NH (1992) Laboratory manual for chemical analysis. Forestry Department, Sandakan

Marsh CW, Greer AG (1992) Forest land-use in Sabah, Malaysia - an introduction to Danum Valley. Proc Roy Soc Lond B Bio 335:331-339

Moura-Costa P, Sau Wai Y, Ong Chye L, Ganing A, Nussbaum R, Mojiun T (1994) Large scale enrichment planting with dipterocarps as an alternative for carbon offset - methods and preliminary results. In: Appanah S, Khoo KC (eds) Proceedings Fifth Round-Table Conference on Dipterocarps. Forest Research Institute Malaysia, Kuala Lumpur

Nicieza AG, Alvarez D (2009) Statistical analysis of structural compensatory growth: how can we reduce the rate of false detection? Oecologia 159:27-39

Nussbaum R, Anderson J, Spencer T (1995) Factors limiting the growth of indigenous tree seedlings planted on degraded rain forest soils in Sabah, Malaysia. Forest Ecol Manag 74:149-159. doi:10.1016/0378-1127(94)03496-J

Nussbaum R, Anderson J, Spencer T (1996) Planting dipterocarps for rehabilitation of log landings and skid trails in Sabah, Malaysia. In: Appanah S, Khoo KC (eds) Proceedings Fifth Round-Table Conference on Dipterocarps. Forest Research Institute Malaysia, Kuala Lumpur

Pinheiro JC, Bates DM (2000) Mixed effects models in S and S-Plus. Springer, New York

Philipson CD (2009) Plant growth analysis of Bornean Dipterocarpaceae seedlings. Dissertation. University Zurich

R Development Core Team (2009) R: A Language and Environment for Statistical Computing. R Foundation for Statistical Computing, Vienna

Raja Barizan RS (1996) Growth and survival of planted seedlings of Hopea odorata under different light conditions and fertiliser levels in a logged-over forest. In: Appanah S, Khoo KC (eds) Proceedings Fifth Round-Table Conference on Dipterocarps. Forest Research Institute Malaysia, Kuala Lumpur

Romell E, Hallsby G, Karlsson A, Garcia C (2008) Artificial canopy gaps in a Macaranga spp. dominated secondary tropical rain forest - effects on survival and above ground increment of four under-planted dipterocarp species. Forest Ecol Manag 255:1452-1460. doi:10.1016/j.foreco. 2007.11.003

Saner P (2005) Does the growth performance of dipterocarp saplings in different light conditions follow an ecological trade-off? Diploma. University Zurich

Saner P (2009) Ecosystem carbon dynamics in logged forest of Malaysian Borneo. Dissertation. University Zurich

Saner P, Lim R, Burla B, Scherer-Lorenzen M, Hector A (2009) Reduced soil respiration in gaps in logged lowland dipterocarp forests. Forest Ecol Manag 258:2007-2012. doi:10.1016/j.foreco.2009.07.048

Scholes JD, Press MC, Zipperlen SW (1997) Differences in light energy utilisation and dissipation between dipterocarp rain forest tree seedlings. Oecologia 109:41-48

Selosse MA, Richard F, He XH, Simard SW (2006) Mycorrhizal networks: des liaisons dangereuses? Trends Ecol Evol 21:621-628

Symington CF (1943) Foresters' manual of dipterocarps. Penerbit Universiti Malaya, Kuala Lumpur

Turjaman M, Tamai Y, Segah H, Limin SH, Osaki M, Tawaraya $\mathrm{K}$ (2006) Increase in early growth and nutrient uptake of Shorea seminis seedlings inoculated with two ectomycorrhizal fungi. J Trop For Sci 18:243-249

Turner IM, Brown ND, Newton AC (1993) The effect of fertilizer application on dipterocarp seedling growth and mycorrhizal infection. Forest Ecol Manag 57:329-337

Venables WN, Ripley BD (2003) Modern applied statistics with S. Springer, New York

Watling JR, Robinson SA, Woodrow IE, Osmond CB (1997) Responses of rainforest understorey plants to excess light during sunflecks. Aust J Plant Physiol 24:17-25

Yasman I (1995) Dipterocarpaceae: tree-mycorrhizae-seedling connections. Dissertation. University Wageningen

Zipperlen SW, Press MC (1996) Photosynthesis in relation to growth and seedling ecology of two dipterocarp rain forest tree species. J Ecol 84:863-876 